\title{
Improving the Management of High-Risk Pregnancies with the Use of the Robson Classification
}

\section{Melhorando a gestão da gravidez de alto risco com o uso da classificação de Robson}

\author{
Mario Dias Correa Junior ${ }^{1}{ }^{10}$ Bárbara Moreira Ribeiro Trindade dos Santos ${ }^{1}$ (1) \\ José Reinaldo Correa Roveda1(1) Laura Carolina Menezes Vieira Silva ${ }^{10}$ Larissa Silva Guimarães ${ }^{20}$ \\ Samuel Cristóvão Lopes Gonçalves ${ }^{10}$
}

1 Faculty of Medicine, Universidade Federal de Minas Gerais, Belo

Address for correspondence Mario Dias Correa Junior, MD, MsC, PhD, Horizonte, MG, Brazil

2 Medical School, Centro Universitário de Belo Horizonte, Belo

Horizonte, MG, Brazil Avenida Alfredo Balena 190, Belo Horizonte, MG, 31270-901, Brazil (e-mail: correajr@gmail.com).

Rev Bras Ginecol Obstet 2020;42(8):448-453.

\section{Abstract \\ Keywords \\ - robson classification \\ - hospital management \\ - maternity \\ - cesarean section \\ - evidence-based clinical practice \\ - birthing centers}

\section{Resumo}

Objective To analyze the rates of cesarean delivery longitudinally in a university hospital using the Robson classification.

Methods Data related to births performed between 2014 and 2018 and recorded in the Maternal and Neonatal Health Information System (Sistema de Informações em Saúde Materna e Neonatal, SISMATER, in Portuguese) were analyzed using the Robson classification. As an aid, we used articles published in the last five years that approach the same topic in other Brazilian maternity hospitals; they were retrieved from the LILACS, MEDLINE, CINAHL, Scopus, Web of Science and Cochrane Library databases. Results There was little variation in the total rate of cesarean sections in the period; however, the profile of each group changed over the years. It was possible to verify a significant reduction in the participation of groups of pregnant women with lower risk and an increase in high-risk pregnancies, attributable to the decrease in beds in the institution, with a greater transfer of patients. In addition, there was a reduction in cesarean sections among the lower-risk groups, while the rate among the higher-risk groups remained stable. Conclusion The use of the Robson classification to stratify cesarean deliveries contributes to a better analysis of the indications for cesarean delivery, enabling the establishment of strategies to reduce the rates, generating a positive impact on hospital management and quality of care.

Objetivo Analisar longitudinalmente as taxas de parto cesáreo em um hospital universitário usando a classificação de Robson.

Métodos Foram analisados, por meio da classificação de Robson, dados relacionados a partos realizados entre 2014 e 2018 e armazenados no Sistema de Informações em Saúde Materna e Neonatal (Sismater). Para auxílio, foram utilizados artigos publicados nos últimos cinco anos que abordavam o mesmo tema em outras maternidades received

October 7, 2019

accepted

May 21, 2020
DOI https://doi.org/

10.1055/s-0040-1713910.

ISSN 0100-7203.
Copyright $\odot 2020$ by Thieme Revinter

Publicações Ltda, Rio de Janeiro, Brazil
License terms

(c) (i) 
Palavras-chave

- classificação de robson

- gestão hospitalar

- maternidade

- cesariana

- prática clínica baseada em evidências

- maternidades brasileiras, tendo como fonte as bases de dados LILACS, MEDLINE, CINAHL, Scopus, Web of Science e Cochrane Library.

Resultados A taxa total de cesárea variou pouco no período; no entanto, alterou-se o perfil de cada grupo ao longo dos anos. Foi possível constatar redução significativa da participação de grupos de contendo gestantes de risco habitual e aumento das gestações de alto risco, atribuíveis à diminuição de leitos na instituição, com maior transferência de pacientes. Além disso, houve uma redução na taxa de cesáreas nos grupos de mais baixo risco, enquanto a taxa dos grupos de risco mais elevado se manteve estável.

Conclusão A utilização da classificação de Robson para estratificar os partos cesáreos contribui para uma análise melhor das indicações do parto cesáreo, o que permite o estabelecimento de estratégias para a redução das taxas, gerando um impacto positivo na gestão hospitalar e na qualidade assistencial.

\section{Introduction}

The first record of a cesarean section (CS) in a live parturient dates back to around 1500, and previously CSs were performed only after maternal death, to save the fetus. Over time, this surgery has improved and is currently considered safe, but it still presents risks for the mother and the newborn. ${ }^{1}$ By definition, $\mathrm{CS}$ is a procedure in which the fetus is removed through an abdominal incision. Such practice, however, does not provide justifiable benefits from the point of view of maternal and newborn health when not indicated, presenting more risks than potential benefits.

What is observed in the world is a tendency to increase the number of CSs. Data published by the World Health Organization (WHO) shows that the percentage rose from $6.7 \%$ to $19.1 \%$ between 1990 and 2014, in an analysis performed in 121 countries. Brazil had CS rates close to $37.8 \% 2$ in 1994 , and in 2014, this type of procedure was performed in $53.88 \%$ of the cases. ${ }^{2}$ Since 1985 , the WHO suggests that CS rates remain between $10 \%$ and $15 \%{ }^{3}$ From a critical point of view, it can be said that this objective is unattainable in certain populations, since it does not take into account the social realities of geosocial stratification.

Although the rate of CS is a good indicator of the access to health services, it is important to emphasize that, from a financial point of view, normal delivery is much more costeffective, and it presents lower risks when well indicated. In addition, the Brazilian government pays the costs of the unnecessary CSs that occur in the public system; therefore, to aim for a better quality of care and a more efficient resource management is fundamental to question the excess of CSs.

In this regard, the WHO, in 2015, suggested the adoption of the Robson classification as a stratification of CSs according to current and previous gestational data in which all pregnant women fit. $^{3}$ This categorization is based on six characteristics: gestational age (term, preterm); obstetric history (nulliparous or multiparous); presence of uterine scar (anterior CS); number of fetuses (single or multiple gestation); fetal presentation (cephalic, pelvic or abnormal); and the way in which the birth developed (spontaneous, induced, CS by choice). This method generates 10 mutually-exclusive and fully-inclusive groups (three of them are also divided into two subgroups), enabling a longitudinal analysis of the pattern for the indication of CSs in each of the selected groups. ${ }^{4}$

In addition to the study from an assistance point of view, it is possible to use the Robson classification to promote strategies on each specific group, making the management methods more objective. Thereby, through the aforementioned stratification, we aimed to longitudinally analyze the CS rates in Hospital das Clínicas, Universidade Federal de Minas Gerais (HC-UFMG). By understanding the variations in these rates, it is possible to determine in which groups we should act to reduce CS rates and also provide subsidies for the improvement of the quality of care, clinical-obstetric outcomes, and the allocation of public resources to a more qualified and humanized service.

\section{Methods}

To carry out the study, we used the set of data related to all deliveries that took place in HC-UFMG between 2014 and 2018 that were recorded in the Maternal and Neonatal Health Information System (Sistema de Informações em Saúde Materna e Neonatal, SISMATER, in Portuguese). Of the total, 99.3\% could be classified in the Robson classification, and the rest were discarded from the present study. The data obtained were analyzed using the Robson classification, with the main objective of performing a longitudinal analysis of CS rates. To carry out the analysis, we searched in the specialized literature articles published between 2015 and 2019 that dealt with the use of the Robson classification in Brazilian maternity hospitals in the following databases: BVS-LILACS (via Bireme), MEDLINE (via PubMed), CINAHL, Scopus, Web of Science and the Cochrane Library. The following descriptors were used: cesarean deliveries (and similar descriptors) together with epidemiology, incidence and prevalence, as well as Robson classification along with epidemiology, incidence, and prevalence. Only the year of publication and the languages (Portuguese, English and Spanish) were used as filters. 
Table 1 Number of cesarean sections in relation to the total number of births per Robson group

\begin{tabular}{|c|c|c|c|c|c|c|c|c|c|c|}
\hline \multirow{2}{*}{$\begin{array}{l}\text { Robson } \\
\text { classification }\end{array}$} & \multicolumn{2}{|l|}{2014} & \multicolumn{2}{|l|}{2015} & \multicolumn{2}{|l|}{2016} & \multicolumn{2}{|l|}{2017} & \multicolumn{2}{|l|}{2018} \\
\hline & $\begin{array}{l}\text { Total } \\
\text { number } \\
\text { of deliveries }\end{array}$ & $\begin{array}{l}\text { Number } \\
\text { (\%) of } \\
\text { cesarean } \\
\text { sections }\end{array}$ & $\begin{array}{l}\text { Total } \\
\text { number } \\
\text { of deliveries }\end{array}$ & $\begin{array}{l}\text { Number } \\
\text { (\%) of } \\
\text { cesarean } \\
\text { sections }\end{array}$ & $\begin{array}{l}\text { Total number } \\
\text { of deliveries }\end{array}$ & $\begin{array}{l}\text { Number } \\
\text { (\%) of } \\
\text { cesarean } \\
\text { sections }\end{array}$ & $\begin{array}{l}\text { Total number } \\
\text { of deliveries }\end{array}$ & $\begin{array}{l}\text { Number } \\
\text { (\%) of } \\
\text { cesarean } \\
\text { sections }\end{array}$ & $\begin{array}{l}\text { Total number } \\
\text { of deliveries }\end{array}$ & $\begin{array}{l}\text { Number } \\
\text { (\%) of } \\
\text { cesarean } \\
\text { sections }\end{array}$ \\
\hline Total deliveries & 2,110 & $761(36.1)$ & 2,110 & $730(34.6)$ & 1,993 & 715 (35.9) & 2,161 & $844(39.1)$ & 1,982 & $785(39.6)$ \\
\hline Group 1 & 507 & 116 (22.9) & 384 & 59 (15.4) & 372 & 65 (17.5) & 352 & $53(15.1)$ & 275 & $42(14.9)$ \\
\hline Group 2 & 229 & $69(30.1)$ & 293 & $116(39,6)$ & 319 & $130(40.8)$ & 322 & 159 (49.4) & 298 & $128(43.0)$ \\
\hline Group 3 & 451 & $27(6)$ & 442 & $28(6.3)$ & 361 & 14 (3.9) & 420 & $22(5.2)$ & 369 & $15(4.1)$ \\
\hline Group 4 & 158 & $34(21.5)$ & 194 & $41(21.1)$ & 200 & 39 (19.5) & 244 & $70(28.7)$ & 234 & $58(24.8)$ \\
\hline Group 5 & 333 & $273(82)$ & 309 & $248(80.3)$ & 297 & $232(78.1)$ & 340 & $286(84.1)$ & 333 & $272(81.7)$ \\
\hline Group 6 & 52 & $43(82.7)$ & 53 & $42(79.2)$ & 60 & $45(75.0)$ & 60 & $46(76.7)$ & 80 & $59(73.8)$ \\
\hline Group 7 & 45 & 34 (61.) & 67 & $50(74.6)$ & 61 & $48(78.7)$ & 69 & $52(75.4)$ & 71 & $52(73.2)$ \\
\hline Group 8 & 52 & $32(61.5)$ & 35 & $19(54.3)$ & 31 & $23(74.2)$ & 47 & $31(66.0)$ & 48 & $34(70.8)$ \\
\hline Group 9 & 14 & $13(92.9)$ & 9 & $9(100.0)$ & 6 & $5(83.3)$ & 12 & $10(83.3)$ & 6 & $5(83.3)$ \\
\hline Group 10 & 258 & $120(46.5)$ & 298 & 108 (36.2) & 271 & $112(41.3)$ & 281 & 109 (38.8) & 262 & $120(45.8)$ \\
\hline $\begin{array}{l}\text { Total number of } \\
\text { cesarean sections } \\
\text { classified }\end{array}$ & 2,099 & 761 (36.3) & 2,084 & 720 (34.5) & 1,978 & $713(36)$ & 2,147 & 838 (39) & 1,976 & $784(39.7)$ \\
\hline
\end{tabular}

\section{Results}

Between 2014 and 2018, there were 10,356 deliveries, 10,284 of which were analyzed according to the Robson ten-group classification. Groups 2, 4 and 5 were not analyzed with the subdivisions due to the fact that the system in which the data was analyzed is from 2013, and, therefore, prior to the current recommendations. The CS rates showed a small variation in the period ( $37.1 \pm 2.6 \%$; - Table 1$)$; however, the profile of each group changed throughout the years ( - Table 2 ). There was a significant decrease in the number of CSs in groups 1 and 3 (from $14.9 \%$ to $8.7 \%$ ). This represents a considerable change, since these groups are usually composed of low-risk patients. In groups 2 and 4 , in which the patients were submitted to induction of labor or CS before the beginning of labor, there was an increase in the rate from $26.6 \%$ to $34.9 \%$, demonstrating that a better analysis should be performed in these groups to identify the causes of this increase. In group 5,-patients with previous $\mathrm{CS}$-, the rates remained unaltered during the period: $81 \%$, which, however, are high rates, indicating that the implementation of effective strategies to encourage vaginal birth after CS (VBACS) may be effective (-Fig. 1). Groups 6, 7 and 8, which are of pelvic and transverse presentation, presented a drop, ranging from $83.1 \%$ to $71.9 \%$. The rates in multiple pregnancies (group 8 ) went from $61.5 \%$ to $70.8 \%$, and in preterm deliveries they remained constant, ranging from $46.5 \%$ to $45.8 \%$ (-Fig. 2).

Regarding the size of each group, groups 1 and 3 decreased from $45.6 \%$ to $32.6 \%$, showing that there was a reduction in the

Table 2 Relative contribution of each Robson group to the total number of cesarean sections

\begin{tabular}{llllll}
\hline Robson classification & \multicolumn{4}{l}{ Participation of each group in the total number of cesarean sections } \\
\cline { 2 - 6 } & $\mathbf{2 0 1 4}(\%)$ & $\mathbf{2 0 1 5}(\%)$ & $\mathbf{2 0 1 6}(\%)$ & $\mathbf{2 0 1 7}(\%)$ & $\mathbf{2 0 1 8 ( \% )}$ \\
\hline Group 1 & 15.20 & 8.20 & 9.10 & 6.30 & 5.20 \\
Group 2 & 9.10 & 16.10 & 18.20 & 19.00 & 16.30 \\
Group 3 & 3.50 & 3.90 & 2.00 & 2.60 & 1.90 \\
Group 4 & 4.50 & 5.70 & 5.50 & 8.40 & 7.40 \\
Group 5 & 35.90 & 34.40 & 32.50 & 34.10 & 34.70 \\
Group 6 & 5.70 & 5.80 & 6.30 & 5.50 & 7.50 \\
Group 7 & 4.50 & 6.90 & 6.70 & 6.20 & 6.60 \\
Group 8 & 4.20 & 2.60 & 3.20 & 3.70 & 4.30 \\
Group 9 & 1.70 & 1.30 & 0.70 & 1.20 & 0.60 \\
Group 10 & 15.80 & 15.00 & 15.70 & 13.00 & 15.30 \\
Total number of cesarean sections classified & 761 & 720 & 713 & 838 & 784 \\
\hline
\end{tabular}




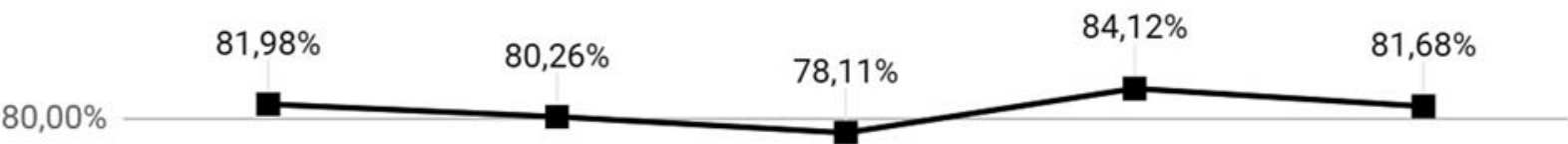

$60,00 \%$

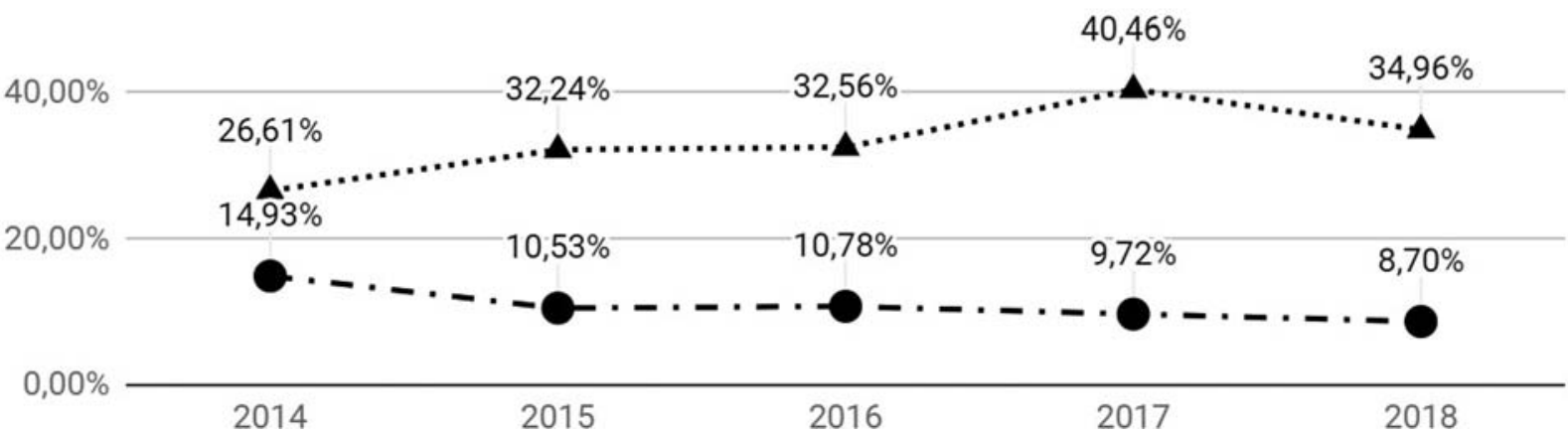

Fig. 1 Comparative analysis of the rate of cesarean section between "groups 1 and 3," "groups 2 and 4" and "group 5".

Group $8 \quad \boldsymbol{\Delta}$ Group 10

Groups 6, 7 and 9

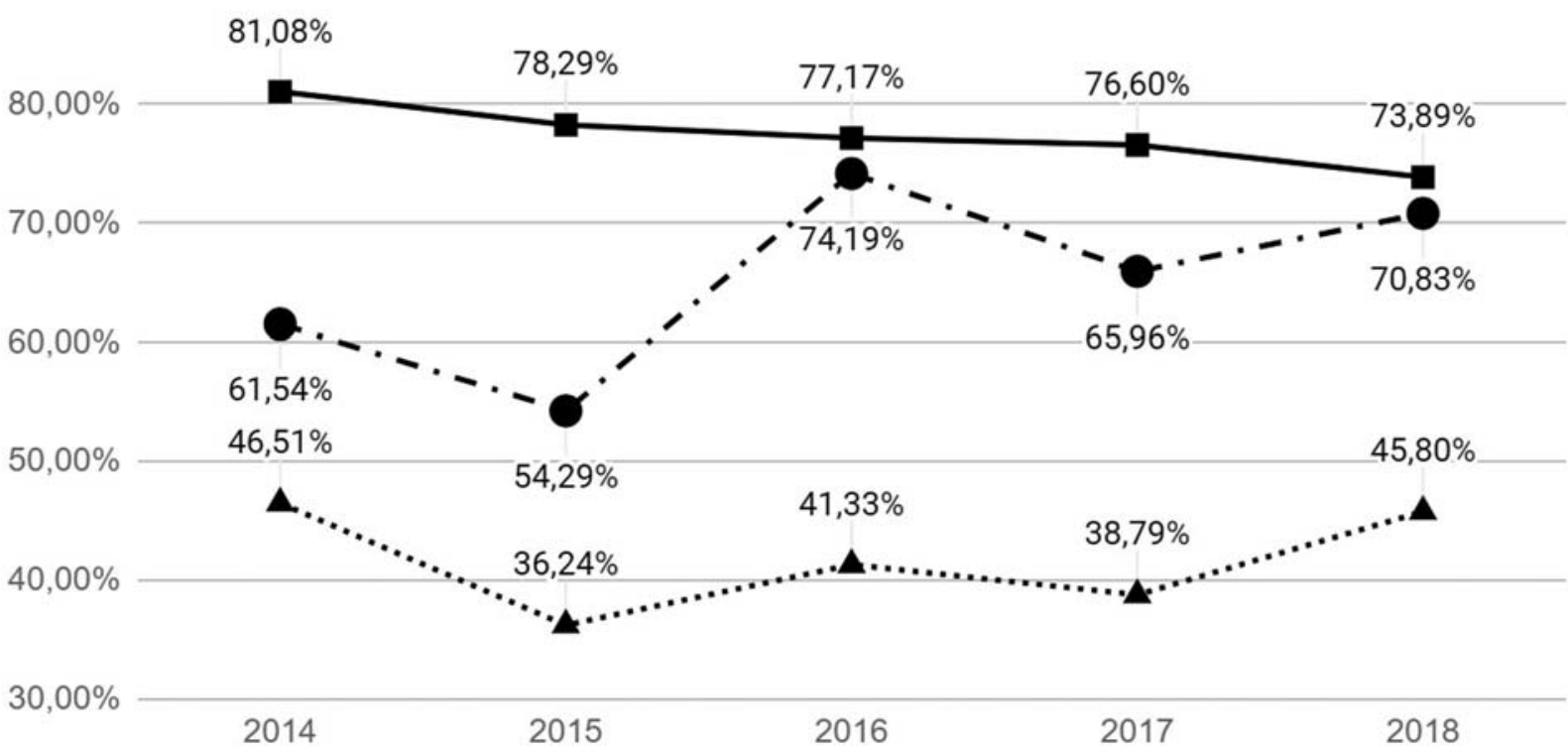

Fig. 2 Comparative analysis of the rate of cesarean section between "group 8," "group 10" e "groups 6, 7 and 9".

number of patients admitted with spontaneous labor, while groups 2 and 4 (induction or elective CS) increased from $18.4 \%$ to $26.9 \%$. These variations are attributed to the reduction in hospital beds in the institution, with greater transference of low-risk patients, giving priority to the hospitalization of more severe patients.

Group 5, in which the women already had a CS, has a high participation rate that has small changes (35.9\% and 34.7\%) (-Table 2). However, the CS rate is around 80\% - the recommended rate is between $50 \%$ and $60 \%$-, which reflects an obstetric fear, since evidence shows that $70 \%$ of vaginal deliveries with previous history of CS have a good evolution, but this group has a higher chance of uterine rupture, which is considered an obstetric emergency.

Groups 6 and 7, which are the ones of pelvic presentation, showed an increase in the rate of CS, which changed from $5.7 \%$ to $7.5 \%$ and from $4.5 \%$ to $6.6 \%$ respectively, which can be considered a reflection of a greater difficulty in transferring patients with an indication for an elective CS to other services. The rates of the multiple-gestation (group 8) and preterm-birth (group 10) groups were constant, ranging from $4.2 \%$ to $4.3 \%$ and $15.8 \%$ to $15.3 \%$, while the gestations with abnormal positions (group 9) showed a reduction from $1.7 \%$ to $0.6 \%$ (-Table 3 ). 
Table 3 The Robson ten-group classification

\begin{tabular}{|c|c|c|}
\hline Group 1 & \multicolumn{2}{|c|}{ Nulliparous, singleton, cephalic, $\geq 37$ weeks of gestation, in spontaneous labor. } \\
\hline \multirow[t]{2}{*}{ Group 2} & Group 2a & Nulliparous, singleton, cephalic, $\geq 37$ weeks of gestation with induced labor. \\
\hline & Group 2b & Nulliparous, singleton, cephalic, $\geq 37$ weeks of gestation with caesarean section before labor. \\
\hline Group 3 & \multicolumn{2}{|c|}{ Multiparous (excluding previous cesarean section), singleton, cephalic, $\geq 37$ weeks of gestation, in spontaneous labor. } \\
\hline \multirow[t]{2}{*}{ Group 4} & Group 4a & Multiparous without a previous uterine scar, singleton, cephalic pregnancy, $\geq 37$ weeks of gestation, induced. \\
\hline & Group 4b & $\begin{array}{l}\text { Multiparous without a previous uterine scar, with singleton, cephalic pregnancy, } \geq 37 \text { weeks of gestation with } \\
\text { cesarean section before labor. }\end{array}$ \\
\hline \multirow[t]{2}{*}{ Group 5} & Group 5.1 & Singleton, cephalic, $\geq 37$ weeks of gestation, with one previous cesarean section. \\
\hline & Group 5.2 & Singleton, cephalic, $\geq 37$ weeks of gestation, with more than one previous cesarean section. \\
\hline Group 6 & \multicolumn{2}{|c|}{ All nulliparous with a single breech. } \\
\hline Group 7 & \multicolumn{2}{|c|}{ All multiparous with a single breech (including previous cesarean section). } \\
\hline Group 8 & \multicolumn{2}{|c|}{ All multiple pregnancies (including previous cesarean section). } \\
\hline Group 9 & \multicolumn{2}{|r|}{ All women with a single pregnancy in transverse or oblique lie (including those with previous cesarean section). } \\
\hline Group 10 & \multicolumn{2}{|c|}{ All singleton, cephalic, <37 weeks of gestatio (including previous cesarean section). } \\
\hline
\end{tabular}

Source: Robson (2001). ${ }^{5}$

\section{Discussion}

In 2001, Dr. Michael Robson published a study ${ }^{5}$ classifying the indications for CS at the National Maternity Hospital in Dublin, Ireland, and his classification was standardized by the WHO in $2015 .^{6}$ Since then, it has been used as a protocol first in European countries and, after that, it has been applied in poorer countries in an effective way all around the world. ${ }^{7,8}$

In Brazil, specialty hospitals created their own protocols based on the Robson classification to monitor their indications for CS as well as to effectively control the financial outcomes. $^{9,10}$ In Brazil, the WHO recommendation was applied to maternity hospitals through the Adequate Childbirth Program - which was proposed by the National Agency for Supplementary Health (Agência Nacional de Saúde Suplementar, in Portuguese) along with Hospital Albert Einstein and the Institute for Healthcare Improvement -, which aims to reduce the CS rates - and the Apice On Project - which was developed by the Nursing School at UFMG with 95 institutions -, whose goal is the humanization of childbirth in the Brazil regarding the basic training of professionals against the rising morbimortality indicators. ${ }^{11-13}$

At the Otto Cirne Maternity of HC-UFMG, the non-subdivision of groups 2, 4 and 5 enabled a better analysis of the risk stratification. Despite that, the management project was able to help reduce the CS rates in low-risk patients (groups 1 and 3), which shows a good alignment to the WHO standards, since they indicate that professionals are adapting to the indications for CS. Even though our CS rate has remained constant, this is due to the type of patients who seek the hospital (high-risk reference), and due to the years with a high CS rate, which results in many patients with previous CS (group 5), which is a possibility of change since in many institutions the VBACS has been offered with a consequent decrease in this group as well.

This classification has shown to be really important in the health management of our maternity hospital, because it has enabled us to obtain knowledge regarding the profile of the patients due to the size of each group. Moreover, it has enabled the observation of the indications for CS, mainly in order for us to make corrections and adjustments. Ultimately, the Robson classification enables the comparison of our data with that of other different maternity hospitals.

\section{Conclusion}

The classification of CSs into subgroups as recommended by the WHO through the Robson classification contributes to a better analysis of the indications for CS, and it also helps to improve the quality of care. Thus, a positive impact on hospital management can be observed, enabling the direct reduction in costs, with better allocation of the budget, with a reduction in expenses regarding non-indicated procedures, and indirectly, with shorter hospitalization time and lower complications involving secondary costs. The present work corroborates the argument that the use of the Robson classification improves the management of the procedures performed in maternity wards, both regarding the assessment of the indication for CS and the continuous revision of the protocols adopted. Thus, the present study shows that there are many future opportunities related to the use of the Robson classification that are applicable to maternity management, something as necessary as desired to positively impact the health of women and children and to direct resources to make health services more accessible and unbiased.

\section{Contributors}

All of the authors contributed with the project and the interpretation of the data, with the writing of the article, the critical review of the intellectual content, and with the final approval of the version to be published.

\section{Conflict of Interests}

The authors have no conflict of interests to declare. 


\section{Acknowledgments}

We would like to thank Hospital São Vicente de Paulo, which is one of the hospitals that integrates the HC-UFMG complex, and especially Otto Cirne Maternity Hospital, for providing the data herein presented; therefore, we extend our thanks to the professionals involved in collecting and recording the information presented in the present article. We would also like to thank the invaluable contribution of Marina Sammarco Eziliano and Daniel Ferreira Diniz Cançado, who were always present and available to help and contribute to the development of the present article.

\section{References}

1 Rezende JM. A primeira operação cesariana em parturiente viva. In: Rezende JM. À sombra do plátano: crônicas de história da medicina. São Paulo: Editora Unifesp; 2009:171-172

2 Ministério da Saúde. DATASUS. Indicadores e Dados Básicos Brasil - 2012 [Internet]. 2013 [cited 2019 Jun 8]. Available from: http://tabnet.datasus.gov.br/cgi/idb2012/matriz.htm

3 Organização Mundial da Saúde. Declaração da OMS sobre taxas de cesáreas [Internet]. 2015 [cited 2019 Jun 8]. Available from: https://apps.who.int/iris/bitstream/handle/10665/161442/ WHO_RHR_15.02_por.pdf?sequence=3

4 World Health Organization. Robson Classification: implementation manual [Internet]. Geneva: WHO; 2017 [cited 2019 Jun 8]. https://apps.who.int/iris/bitstream/handle/10665/259512/ 9789241513197-eng.pdf? sequence $=1$

5 Robson MS. Classification of caesarean sections. Fetal Matern Med Rev. 2001;12(01):23-39. Doi: 10.1017/S0965539501000122

6 Boatin AA, Cullinane F, Torloni MR, Betrán AP. Audit and feedback using the Robson classification to reduce caesarean section rates: $a$ systematic review. BJOG. 2018;125(01):36-42. Doi: 10.1111/14710528.14774

7 Triunfo S, Ferrazzani S, Lanzone A, Scambia G. Identification of obstetric targets for reducing cesarean section rate using the Robson Ten Group Classification in a tertiary level hospital. Eur J Obstet Gynecol Reprod Biol. 2015;189:91-95. Doi: 10.1016/j. ejogrb.2015.03.030

8 Yadav RG, Maitra N. Examining cesarean delivery rates using the Robson's Ten-group Classification. J Obstet Gynaecol India. 2016; 66(Suppl 1):1-6. Doi: 10.1007/s13224-015-0738-1

9 Ferreira EC, Pacagnella RC, Costa ML, Cecatti JG. The Robson tengroup classification system for appraising deliveries at a tertiary referral hospital in Brazil. Int J Gynaecol Obstet. 2015;129(03): 236-239. Doi: 10.1016/j.ijgo.2014.11.026

10 Nakamura-Pereira M, do Carmo Leal M, Esteves-Pereira AP, et al. Use of Robson classification to assess cesarean section rate in Brazil: the role of source of payment for childbirth. Reprod Health. 2016;13(Suppl 3):128. Doi: 10.1186/s12978-016-0228-7

11 Agência Nacional de Saúde Suplementar, Sociedade Beneficente Israelita Brasileira Hospital Albert Einstein, Institute for Healthcare Improvement. Cartilha nova organização do cuidado ao parto e nascimento para melhores resultados de saúde: Projeto Parto Adequado - fase 1 [Internet]. Rio de Janeiro: ANS; 2016 [cited 2019 Jun 9]. Available from: http://www.ans.gov.br/images/stories/Materiais_para_pesquisa/Materiais_por_assunto/web_total_ parto_adequado.pdf

12 Ministério da Saúde. Secretaria de Atenção à Saúde. Apice on: aprimoramento e inovação no cuidado e ensino em obstetrícia e neonatologia [Internet]. Brasília (DF): Ministério da Saúde; 2017 [cited 2019 Jun 9]. Available from: https://portalarquivos.saude. gov.br/images/pdf/2017/agosto/18/Apice-On-2017-08-11.pdf

13 Mascarello KC, Horta BL, Silveira MF. Maternal complications and cesarean section without indication: systematic review and meta-analysis. Rev Saude Publica. 2017;51:105. Doi: 10.11606/ s1518-8787.2017051000389 